\title{
Non-specific Activities against Ruthenium Crosslinker as a New Cause of Assay Interference in an Electrochemillumi- nescent Immunoassay
}

\author{
Takao Ando ${ }^{1}$, Jun-ichi Yasui ${ }^{1}$, Naoko Inokuchi ${ }^{2}$, Toshiro Usa ${ }^{1}$, \\ Kiyohito Ashizawa ${ }^{1}$, Shimeru Kamihara ${ }^{2}$ and Katsumi Eguchi ${ }^{1}$
}

\begin{abstract}
Clinical assays are very important for the diagnosis and management of clinical disorders. Each assay system consists of a specific method to detect and/or quantify a substance of interest in the clinical specimen. However, clinical assays can be unfavorably influenced by non-specific activities concomitantly present in the specimen, which may mislead clinical decisions. Thus, it is very important to know how each assay works, and how and when the assay is non-specifically influenced. Here, we report three cases shown clinical data of thyroid function influenced by new type of assay interference.
\end{abstract}

Key words: assay interference, thyroid hormone, SITSH, nonspecific activities

(DOI: 10.2169/internalmedicine.46.0188)

\section{Introduction}

It is critically important to know the precise serum levels of hormone(s) of interest when endocrine diseases are considered in the differential diagnosis. However, because of their low concentrations in blood, a clinical assay consisting of complicated antigen (hormone)-antibody binding reaction has been developed and utilized. This has been a timeconsuming and labor-requiring step. Recently, by utilizing electrochemilluminescent immunoassay (ECLIA), blood levels of hormones can be quickly available in an automated system within an hour $(1,2)$. This improvement significantly contributes to rapid diagnosis of and better management of patients with endocrine disease.

Appearance of an ECLIA may be more beneficial to patients with thyroid diseases because the thyroid is affected most commonly among the endocrine glands. Serum levels of thyroid hormones determined in the clinical assay including ECLIA are in general reliable, corresponding well with clinical findings. However, a couple of factors present in sera have been recognized to influence the clinical assay, therefore, the levels of hormones measured can be unaccept- ably lower or higher than the actual ones. These results can lead to an incorrect diagnosis as well as an inappropriate treatment. These factors include anti-animal antibodies (3) and anti-hormone antibodies $(4,5)$.

Anti-animal antibodies interfere antigen (= hormone of interest) specific antibody binding in the clinical assay. Antianimal antibodies can be against any species of animals including mouse, sheep, rabbit, and goat (3). Therefore, assay interference can be seen when anti-animal antibodies bind to animal derived-antibodies employed in the assay. It has been known that capture type assay, which utilizes two different antibodies against antigen for measurement, is affected more frequently than the assay that uses only one antibody (3). Anti-hormone antibodies are against hormone itself. These antibodies may influence clearance of a hormone (6). Thyroid hormone is one of the well-known targets for autoantibodies. This could be due to thyroid hormone being synthesized on the thyroglobulin, one of the major autoantigens in autoimmune thyroid disease.

SITSH, which stands for syndrome of inappropriate secretion of TSH, is clinical condition with normal or high serum levels of TSH in the presence of high serum levels of thyroid hormones $(7,8)$. SITSH is seen in a patient with pitui-

${ }^{1}$ First Department of Medicine, Nagasaki University of Medicine, Nagasaki and ${ }^{2}$ Department of Laboratory Medicine, Nagasaki University of Medicine, Nagasaki

Received for publication March 23, 2007; Accepted for publication April 17, 2007

Correspondence to Dr. Takao Ando, takaoando@gmail.com 
tary adenoma producing $\mathrm{TSH}$ and those with resistance to thyroid hormone, both being extremely rare. However, clinical assay showing SITSH is more frequently encountered due to assay interference as mentioned above. Here we report three cases showed clinical data compatible with SITSH caused by a new type of assay interference.

\section{Case Report}

\section{Case 1}

A 66-year-old female was referred to our hospital in June 2006 because of thyroid nodules. We measured her thyroid hormones, free $\mathrm{T} 3$, free $\mathrm{T} 4$, and $\mathrm{TSH}$, since her thyroid gland, including nodules, showed a diffuse increase in blood flow as determined by echosonography. Her thyroid hormone levels were compatible with SITSH and the data were reproducible (Table 1) although there were no clinical symptoms or signs related to thyrotoxicosis. We carried out MRI examination of the pituitary gland, which showed that her pituitary seemed to contain a small lesion slowly enhanced as compared to the normal tissue (data not shown). Therefore, we considered that she may have TSH-secreting pituitary tumor causing SITSH. She was admitted to our hospital for further examination of SITSH in August 2006. However, to our surprise, serum levels of free T3 on her admission were normalized while free T4 and TSH remained unchanged (Table 1). Her thyroid had never been treated. Thyroid autoantibodies including antibodies to thyroglobulin, thyroid peroxidase, and TSH receptor (this included TSH binding inhibitory antibodies and TSH receptor stimulating antibodies), were all negative. TRH test showed a rather exaggerated response of TSH increasing from 3.65 to 24.29 $\mathrm{IU} / \mathrm{ml}$ at $30 \mathrm{~min}$. Radioiodine uptake of her thyroid was $18 \%$ excluding hyperactivity of this endocrine gland. These findings, taken together, highly suggested that thyroid hormone data compatible with SITSH were not due to TSH secreting pituitary adenoma or resistance to thyroid hormone resistance.

\section{Case 2}

A 50-year-old female was referred to our hospital in June 2006 because of her refractory Graves disease not responding to three years of antithyroid drug treatment (200-300 $\mathrm{mg}$ /day of propiothiouracil). Her serum levels of TSH were undetectable when she first had symptoms of thyrotoxicosis and she was positive for TSH receptor antibodies $(20 \%$ as determined by first generation assay). Serum levels of thyroid hormone remained high, however, serum levels of TSH were being measurable one year after the treatment. She was clinically euthyroid when we examined, however, serum levels of her thyroid hormone were consistent with SITSH, and similar to those obtained at the clinic (Table 1). She did not have any suspicious lesions in the pituitary gland when studied by MRI. Higher dose of antithyroid drug (up to 450 $\mathrm{mg} /$ day) did not at all decrease her serum levels of thyroid
Table 1. Serum Levels of Thyroid Hormones in Three Patients Compatible with SITSH

\begin{tabular}{|c|c|c|c|c|}
\hline Case 1 & June & July & Aug & Sep \\
\hline Free T3 (pg/ml) & $12.12(3.93)^{1}$ & ${ }^{1} 13.86$ & 3.49 & $3.40(3.40)^{2}$ \\
\hline Free T4 (ng/dl) & 1.99 & 2.04 & 2.16 & $2.03(1.10)^{2}$ \\
\hline TSH $\quad(\mathrm{ulU} / \mathrm{ml})$ & 4.4 & 5.62 & 4.49 & $4.06(3.81)^{2}$ \\
\hline Case 2 & June & July & Aug & Sep \\
\hline Free T3 $(\mathrm{pg} / \mathrm{ml})$ & $8.79(3.76)^{1}$ & 7.32 & 3.35 & $3.19(3.10)^{2}$ \\
\hline Free T4 (ng/dl) & 1.89 & 1.5 & 1.7 & $1.81(1.11)^{2}$ \\
\hline TSH $\quad(\mathrm{ulU} / \mathrm{ml})$ & 6.11 & 4.9 & 5.89 & $3.54(\mathrm{ND})^{3}$ \\
\hline Case 3 & Oct/1997 & Feb & Apr & Oct \\
\hline Free T3(pg/ml) & 3.4 & $7.71(5.92)^{1}$ & 7.14 & $5.8(3.26)^{2}$ \\
\hline Free T4(ng/dl) & 1.1 & 1.95 & 2.07 & $2.08(1.23)^{2}$ \\
\hline TSH $\quad(\mathrm{ulU} / \mathrm{ml})$ & 1.71 & 1.55 & 1.51 & $2.24(\mathrm{ND})^{3}$ \\
\hline
\end{tabular}

Reference levels are from 2.37 to 3.91 for free $\mathrm{T} 3$, from 0.95 to 1.57 for free T4, and 0.48 to 5.08 for TSH. Values indicated as bold were out of the each reference range. Dates shown are of year 2006, indicating month of hormone measurement otherwise specified. ${ }^{1}$ indicates serum levels of free T3 determined by using a free T3 ECLIA with modification (see text for details). ${ }^{2}$ indicates serum levels of indicated hormones determined by using CLIA. ${ }^{3} \mathrm{ND}$ indicates not done.

hormone whereas her serum levels of total cholesterol increased from 240 to $280 \mathrm{mg} / \mathrm{dl}$, which suggested that there might be an assay interference involved in determination of her serum levels of thyroid hormone and she might be rather hypothyroid. While treating this patient, her serum levels of free T3 similarly changed and normalized in August 2006.

\section{Case 3}

A 45-year-old male has been treated with subcutaneous insulin because of his fluminant insulin dependent diabetes developed when he was 36 years. Since he was positive for thyroid peroxidase antibodies $(29.1 \mathrm{U} / \mathrm{ml}$, negative being < $0.3 \mathrm{U} / \mathrm{ml}$ ), his thyroid function was followed periodically and he had been euthyroid clinically as well as biochemically as determined by radioimmunoassay. However, his serum levels of thyroid hormones increased suddenly in Feb. 2006 while serum levels of TSH remained normal (Table 1) without showing any signs or symptoms of thyrotoxocosis, or worsening of his diabetes. His abnormal thyroid function was reproducible, therefore, we examined his thyroid by using echosonography, showing no enlargement or increased intrathyroidal blood flow. We strongly suspected that he was euthyroid and there should be some kind of assay interference. High serum levels of free T3 decreased slightly in Au- 
Table 2. Influence of PEG Precipitation on Levels of Free T3 of Sera from Three Patients

\begin{tabular}{lclll}
\hline & without modification & \multicolumn{2}{l}{ with modification } \\
\hline PEG & $(-)$ & $(+)$ & $(-)$ & $(+)$ \\
\hline Case 1 & $\mathbf{1 1 . 7 9}$ & 2.83 & 3.93 & 3.27 \\
Case 2 & $\mathbf{8 . 7 3}$ & 2.76 & 3.76 & 3.26 \\
Case 3 & $\mathbf{7 . 7 4}$ & 2.93 & $\mathbf{5 . 9 2}$ & 2.94 \\
\hline
\end{tabular}

Test sera were mixed with the same volume of $25 \%$ PEG6000 by vortex and supernatant was obtained by centrifuging at $5000 \mathrm{~g}$. Levels of free T3 in the supernatant were determined by ECLIA and duplicated values are shown. Reference levels for free T3 are from 2.37 to 3.91 (pg/ml). Values indicated as bold were out of the each reference range. See text for the difference between ECLIA with or without modification.

gust 2006, but still remained high (Table 1).

Since these patients were clinically euthyroid and the serum levels of free T3 were normalized or decreased without treatment, we strongly suspected that there would be an assay interference especially for free T3. It was clear that the sudden decrease of the serum levels of free T3 seen in these patients, as suggested by cases 1 and 2, occurred between July and August 2006. Actually this was the exact same time that Roche Diagnostic, who provides the ECLIA assay (Eclusis FT3II) for thyroid hormones to our University hospital, introduced a minor change to the clinical assay for free T3. This was done in order to absorb non-specific activities against Ruthenium crosslinker complex (see below) present in rare sera (less than $0.1 \%$ ) and this modification should decrease serum levels of free T3 only marginally ( 2 to $3 \mathrm{pg} / \mathrm{ml}$ ) in such sera (taken from commercial leaflets from Roche).

However, the change of serum levels of free T3 we observed here was significant $(\sim 5,10 \mathrm{pg} / \mathrm{ml}$ in cases 1 and 2 , respectively) and nonetheless confusing. We asked Roche Diagnostic to measure the serum levels of free T3 by using their kit with and without the modification (Table 2). These data clearly showed that the aberrantly high serum levels of free T3 in cases 1 and 2 seen in the serum specimens obtained in June 2006 were simply due to non-specific activities against the Ruthenium-crosslinker complex. In case 3, a decrease in free T3 seen was also due to similar nonspecific activities. Such non-specific activities seen these cases including case 3 can be alleviated by precipitation of sera with polyethylene glycol (PEG) (Table 2), suggesting that immunoglobulin might be involved. It seemed that the assay interferences seen in these patients were specific to ECLIA employed in our hospital since the serum levels of thyroid hormones were compatible with their clinical findings when measured by another type of assay (CLIA and RIA) (Table 1). Therefore, cases 1 and 2 seemed to be subclinical hypothyroidism, as indicated by the slightly elevated serum levels of TSH. This was supported by an exaggerated TSH response to TRH in case 1 . In case 2 it could be due to inappropriate antithyroid drug treatment.

Finally, we have looked at all the thyroid hormone measurements performed in our University hospital after the ECLIA was employed (since May 2005). There were in total 7567 simultaneous measurements of free T3, free T4, and TSH (actual number of patients should be much less because of multiple measurements in the identical patients under periodical follow) and we examined these data to see if any had serum levels of free T3 and TSH higher than $5 \mathrm{pg}$ / $\mathrm{ml}$ AND $1 \mathrm{uIU} / \mathrm{ml}$, respectively. We could not find any patients other than described above.

\section{Discussion}

An ECLIA for free T3 quantifies a photon released from an excited Ruthenium label located at the specific antibody against free T3 attached as Ruthenium (II) tris (bipyridyl) ${ }_{3}{ }^{2+}$ (crosslinker being underlined)(Fig. 1). In this assay system, the higher the serum levels of free T3 are, the less the signal is generated in the assay. Serum levels of free T4 are measured in an almost identical ECLIA system for free T3. The only the difference between them is the specific antibody to the corresponding hormone. Free T3 assay uses sheepderived monoclonal antibody whereas free T4, uses sheep polyclonal. In an ECLIA for TSH, Ruthenium cross linker is attached to TSH, not to specific antibody to TSH and the higher the signal obtained, the higher the TSH concentrations.

We have shown here that sera from three patients contained non-specific activities which interfere with an ECLIA assay for free T3, as demonstrated by their disappearance as seen in cases 1 and 2 by the addition of free Ruthenium crosslinker in the assay buffer. Such activities can also be precipitated with PEG, suggesting immunoglobulin may be involved. We believe that sera from case 3 contained stronger, either of the higher concentrations and/or higher affinity, assay interfering activities than other cases, but still specific to Ruthenium crosslinker. This is because PEG could precipitate the activities and also because hormone values obtained in a CLIA using sheep-derived antibody exclude involvement of anti-animal antibodies. These sera also seemed to interfere, at least partially, with free T4 assay, as suggested by discrepancy of the values between an ECLIA and CLIA. Unfortunately, we could not confirm if this was the case this time due to unavailability of free Ruthenium crosslinker complex.

Sapin et al (9) have very recently found the similar assay interference in five sera that could be eliminated by adding free Ruthenium crosslinker. These sera did not interfere with free T4 assay although they did not provide the actual data. This could be due to weaker and/or less interference (serum levels of free T3 determined decreased from 5.2 \pm 0.70 to $3.87 \pm 0.78 \mathrm{pg} / \mathrm{dl}$ by adding free Ruthenium crosslinker in the assay buffer) compared to those of the present study. Indeed, 

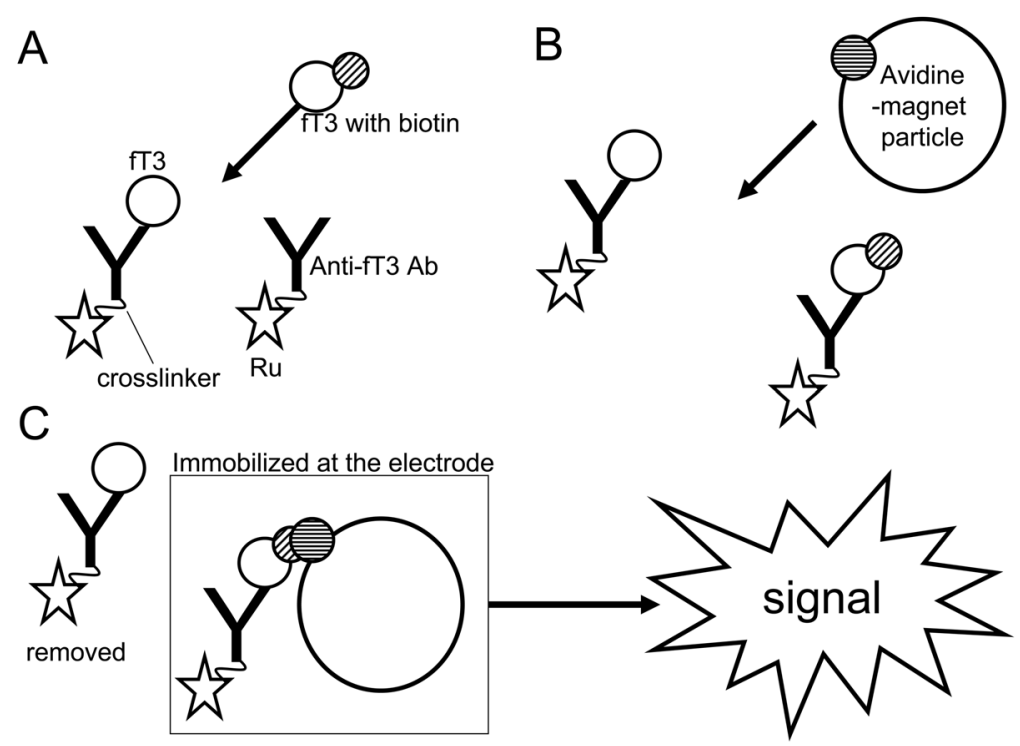

Figure 1. An ECLIA for free T3. Ruthenium (indicated as Ru) labeled anti-free T3 antibody (Anti-fT3 Ab) is incubated with a test serum and, then, free T3 labeled with biotin (fT3 with biotin) is added to occupy any unbound antibody (A), which consequently forms a complex with magnetic particle labeled with avidin (Avidine-magnet particle) (B). This complex, Ruthenium labeled antibody-free $\mathrm{T} 3$ labeled with biotin-magnetic particle with avidin, is immobilized at the surface of the electrode in order to collect antibody bound to free T3 labeled with biotin, and to undergo the electrochemiluminescent detection (C).

the levels of interference were very similar to what were informed by Roche ( 2 to $3 \mathrm{pg} / \mathrm{ml}$ ).

Non-specific activities seen in these cases somehow decreased the signal generated in an ECLIA. Considering the assay system as illustrated in Fig. 1, non-specific activities should bind Ruthenium labeled antibodies and, therefore, more antibodies would be driven to the electrode. More Ruthenium would excite and, therefore hormone levels determined would be less. However, here we obtained higher values than the actual ones, therefore, the non-specific activities seemed to diminish the signal generated in an ECLIA system. In a recent study by Sapin et al (9); they mentioned that these non-specific activities block T3 binding to antibody against free T3, giving higher free T3 values. However, there were no accompanying data to support this mechanism. Therefore, the precise mechanism(s) for assay interference caused by these sera was difficult to understand per se. It was also not certain why these sera did not interfere TSH assay.

Non-specific activities seen in these patients may not be so rare. As mentioned, three cases presented herein were all the cases we could find in our university hospital. Considering multiple measurements in an identical patient, up to 1 in 1000 individuals may have such activities and this is comparable to the one Roche informed (less than $0.1 \%$ ) as well as that Sapin et al reported $(\sim 0.2 \%)$ (9). Although the company providing the assay have noticed and overcome this problem in free T3 assay, the similar assay interference seemed to be involved in free T4 assay as well. Although we were not able to find any reports published, identification of three cases described herein and five cases reported by Sapin et al (9) may suggest that there may be a similar interference in clinical assay using other reagents, such as peroxidase and alkaline phosphatase for detection. As expanding use of ECLIA in determining a substance present in a specimen at low concentrations, we should know how the levels of substance of interest are determined and give more credit on clinical signs and symptoms than the assay results, if not corresponding each other.

We thank Mr. Yotaro Shimokawa in Roche Diagnostic Japan for his technical support.

\section{References}

1. Sanchez-Carbayo M, Mauri M, Alfayate R, Miralles C, Soria F. Analytical and clinical evaluation of TSH and thyroid hormones by electrochemiluminescent immunoassays. Clin Biochem 32: 395-403, 1999.

2. Forest JC, Masse J, Lane A. Evaluation of the analytical performance of the Boehringer Mannheim Elecsys 2010 immunoanalyzer. Clin Biochem 31: 81-88, 1998.
3. Kricka LJ. Human anti-animal antibody interferences in immunological assays. Clin Chem 45: 942-956, 1999.

4. Premachandra BN, Blumenthal HT. Abnormal binding of thyroid hormone in sera from patients with Hashimoto's disease. J Clin Endocrinol Metab 27: 931-936, 1967.

5. Staeheli V, Vallotton MB, Burger A. Detection of human antithyroxine and anti-triiodothyronine antibodies in different thyroid 
DOI: $10.2169 /$ internalmedicine.46.0188

conditions. J Clin Endocrinol Metab 41: 669-675, 1975.

6. Fahie-Wilson MN, John R, Ellis AR. Macroprolactin; high molecular mass forms of circulating prolactin. Ann Clin Biochem 42: 175-192, 2005.

7. Beck-Peccoz P, Brucker-Davis F, Persani L, Smallridge RC, Weintraub BD. Thyrotropin-secreting pituitary tumors. Endocr Rev 17: 610-638, 1996.
8. Gershengorn MC, Weintraub BD. Thyrotropin-induced hyperthyroidism caused by selective pituitary resistance to thyroid hormone. A new syndrome of "inappropriate secretion of TSH". J Clin Invest 56: 633-642, 1975.

9. Sapin R, Agin A, Gasser F. Efficacy of a new blocker against antiruthenium antibody interference in the Elecsys free triiodothyronine assay. Clin Chem Lab Med 45: 416-418, 2007.

(C) 2007 The Japanese Society of Internal Medicine http://www.naika.or.jp/imindex.html 